\title{
Editorial: Current Topics in Marine Organic Biogeochemical Research
}

\author{
Stuart G. Wakeham ${ }^{1 *}$, Cindy Lee ${ }^{2}$, Carol Arnosti ${ }^{3}$, Thorsten Dittmar ${ }^{4}$, Kai-Uwe Hinrichs ${ }^{5}$ \\ and Ann Pearson ${ }^{6}$
}

'Skidaway Institute of Oceanography, University of Georgia, Savannah, GA, United States, ${ }^{2}$ School of Marine and Atmospheric Sciences, Stony Brook University, Stony Brook, NY, United States, ${ }^{3}$ Department of Marine Sciences, University of North Carolina-Chapel Hill, Chapel Hill, NC, United States, ${ }^{4}$ Institute for Chemistry and Biology of the Marine Environment (ICBM) and Helmholtz Institute for Functional Marine Biodiversity (HIFMB), Carl von Ossietzky University of Oldenburg, Oldenburg, Germany, ${ }^{5}$ MARUM - Center for Marine Environmental Sciences, University of Bremen, Bremen, Germany, ${ }^{6}$ Department of Earth and Planetary Sciences, Harvard University, Cambridge, MA, United States

Keywords: marine organic biogeochemistry, dissolved organic matter, particulate organic matter, sedimentary organic matter, analytical challenges

\section{Editorial on the Research Topic}

\section{Current Topics in Marine Organic Biogeochemical Research}

Complex and incompletely understood chemical, biological and physical processes affect the delivery, transport, and storage of organic matter (OM) in the ocean. Atmospheric and climaterelevant gases, primarily carbon dioxide, are closely linked to the production and flux of organic matter within the ocean via the biological pump. Marine and continental OM is transformed in the water column, some is transported to the sediments where a fraction is stored over geological time, and some marine $\mathrm{OM}$ is released to the atmosphere. These functions are intimately linked to global nutrient cycles and ecosystem processes. Perhaps indicative of how the field has matured, the multidisciplinary nature of ocean carbon studies and the importance of biological processes in organic carbon cycling has resulted in a morphing of "marine organic geochemistry" into "marine organic biogeochemistry." Marine organic biogeochemistry now provides a molecular-level window onto the functioning and scale of processes that control the behavior of OM in the ocean. New sampling tools, analytical methods, and data handling capabilities have been applied to marine chemistry since the 1970s; and in tandem with coordinated, international and interdisciplinary research programs, this has led to explosive growth of marine organic biogeochemistry.

More than four decades have passed since the first community-wide marine organic geochemistry workshop was held in 1976 to assess progress, identify continuing challenges, and recommend future research needs (Andersen, 1977). Major topics at that workshop were: (i) global biogeochemical cycles; (ii) macromolecular material; (iii) transformations in the water column; (iv) diagenesis in sediments; (v) molecular paleontology; and (vi) physical organic chemistry. Follow-on symposia in 1990 (Farrington, 1992), 1999 (Hedges et al., 2000), and 2003 (Benner et al., 2004) provided updates via cross-disciplinary exchange of ideas and new concepts to address analytical, methodological and conceptual questions pivotal to the field of marine organic biogeochemistry. Several recent reviews (summarized by Wakeham and Lee, 2019) have placed marine organic geochemistry within the context of the oceanic carbon cycle and biogeochemistry as it is understood today.

This special issue highlights a workshop that was held at the Hanse Wissenschaftskolleg (HWK Institute for Advanced Studies, Delmenhorst, Germany) in April 2019 and that was designed to stimulate discussion about current topics in molecular marine organic biogeochemical research 
among scientists working on multiple aspects of biogeochemistry. Marine OM covers a wide size continuum that includes particulate (POM), colloidal (COM), and dissolved (DOM) phases that are largely operationally defined. There is considerable overlap in their analyses and biogeochemical processes. Of particular interest to the workshop were the links between production and fluxes of OM in the ocean and the roles these processes play in ocean biogeochemical cycles. The goals of the workshop were to develop (i) a better understanding of organic biogeochemical processes in the ocean; (ii) a clear picture of the most important gaps in knowledge; and (iii) a path forward toward addressing these deficiencies. Discussion groups were constituted for three broad themes (POM, DOM, and analytical methods) and the three working group reports included here assess the state-of-the-art for each theme and highlight needs and challenges for future research. Additionally, 17 articles were contributed within these broad themes and center on other aspects of organic biogeochemistry, biological processing of organic materials, isotope biogeochemistry, and analytical advances.

The working group on POM (Kharbush et al.) uses an overview of autochthonous, allochthonous, and anthropogenic components of oceanic particulate organic carbon (POC) to assess recent progress in understanding its distribution in the ocean, its composition and its cycling. This report suggests various research directions needed to bridge diverse databases that can link the identity and structural diversity of POC to its sources and transformation processes. The DOM working group report (Wagner et al.) synthesizes fluxes of oceanic dissolved organic carbon (DOC), considers what is meant by DOC "recalcitrance," spotlights new isotopic approaches for probing the distribution of DOC in the ocean, and postulates changes to DOC quantity and composition that may occur in response to climate change. The analytical working group (Steen et al.) compiles examples of recent developments in analytical methods that have made possible transformative advances in marine organic biogeochemistry over the past decade and projects some challenges and opportunities for the future to insure continued evolution in understanding the cycling of organic carbon in the ocean. Collectively, these summaries set the stage for indepth exploration of the three focus areas and provide contextual framework for the discipline-focused articles.

Recent progress in understanding the composition and biogeochemical behavior of DOM is described in two articles. Srain et al. investigate pathways of organic carbon degradation in the oxygen minimum zone within the Humboldt Current off the coast of Chile. Over a 15-month period, concentrations of volatile fatty acids, ethanol, and $\mathrm{CO}_{2}$, typical products of fermentation reactions, were measured at different depths in the upper water column. Incubation experiments with added amino acids, glucose, and acetate, were also carried out to link water column concentrations in the seasonally changing environment with potential transformation pathways of organic matter. Ziervogel and Arnosti measured the activities and substrate specificities of microbial extracellular enzymes in waters of the Guaymas Basin (Gulf of California), where hot hydrothermal fluids "cook" the thick layers of phytoplankton-derived organic matter in surficial sediments, yielding high concentrations of DOC that permeate into bottom waters. Enzyme activities in the deepest part of the water column are similar to or higher than in the upper water column, and are measurable for a broader spectrum of substrates, suggesting that sediment-derived DOC enhances microbial activities in bottom water.

Seven articles focus on various aspects of POM. van der Jagt et al. provide direct evidence that filter-feeding copepods are responsible for much of the attenuation in aggregate POC flux in the Arctic Ocean near Svalbard by directly ingesting and fragmenting settling marine snow. Optical systems that can obtain vertical profiles of particle size-distribution and abundance are often used to estimate POC fluxes and distributions in the water column. By combining different optical systems to detect a range of organic and inorganic particle types, Markussen et al. show that better estimates of fluxes of both small and large particles can be obtained. Using cell membrane derived intact polar lipids (IPLs) as biomarkers, Cantarero et al. find major differences between the oxygen minimum zone off Chile and other similar areas. These IPLs indicate contrasting distributions of free-living and particle-attached microbes and also suggest that microbial production in low oxygen environments may be more important than previously thought. Close and Henderson have compiled published reports of stable carbon isotope compositions $\left({ }^{13} \mathrm{C}\right.$ values) of POC in the upper water column that show a widespread isotopic pattern in oceanic POC. They further discuss the implications of this pattern in terms of vertical differences in algal photosynthetic growth rates or algal community composition, effects of degradation on the composition of POM, isotopic disequilibrium within the dissolved inorganic carbon pool, particle dynamics, and vertical mixing processes. The stable carbon isotope signature of POC and particulate amino acids in the hypoxic water column of the northern South China Sea were investigated by Yang et al. to better understand the sources and cycling of OM in the coastal environment. These authors found no apparent differences in the carbon isotopic distributions of particulate amino acids between hypoxic and oxic waters. Engel et al. review the widespread abundance of two major types of microgels throughout the ocean in terms of their importance to DOC. They discuss how microgel distributions provide information about productivity and particle dynamics in the ocean. Le Moigne assembles published studies that quantify sinking fluxes of fecal pellets, phytoplankton cells, and aggregates, as well as the redistribution of organic matter via physical mixing processes and via migration. He points out knowledge gaps that affect estimates of the biological pump, and potential means to address them.

Organic biogeochemistry of sedimentary environments and sedimentary organic matter is discussed in four articles. In a study of bottom waters and sediment porewaters at sites spanning the eastern to western Fram Strait, Rossel et al. report DOC concentrations and molecular composition, finding that regional and interannual differences in sediment DOC concentration can be linked to surface productivity differences in this variably ice-covered region. Bao and Blattmann discuss insights gained from and challenges remaining to using natural abundance radiocarbon $\left({ }^{14} \mathrm{C}\right)$ of sinking POM and sedimentary 
$\mathrm{OM}$ to better characterize source-to-sink dynamics in the contemporary ocean, using the East Asian Seas as model systems. Bacteriohopanepolyols (BHPs), which are important biomarkers for bacterial cell membranes, are investigated by Kusch, Sepulveda et al.; Kusch, Benthien et al. in densityfractionated sediments from the highly dynamic Mississippi River Delta and adjacent coastal Gulf of Mexico to assess the provenance and hydrodynamic sorting of particulate matter as it is transported across the continental shelf. Arnosti et al. discuss unsolved questions related to sedimentary microbial communities and uncharacterized sedimentary organic matter, and suggest several specific research focal points that would help answer these questions.

Recent progress in application of new analytical methodologies to marine organic biogeochemistry is reported in the final four articles. Rattray and Smittenberg describe an improved high-pressure liquid chromatography approach for measuring the analytically challenging diversity of structural and stereoisomers of glycerol dialkyl glycerol tetraethers. These compounds have gained wide usage as biomarkers in marine and terrestrial research. The remaining three articles address natural abundance radiocarbon $\left({ }^{14} \mathrm{C}\right)$ measurements, particularly at the compound-specific level. Blattmann and Ishikawa discuss how compound-specific radiocarbon analysis can shed light on the turnover, age, and sources of a range of biomarkers in various environmental matrices. They particularly address the research potential of amino acid-specific radiocarbon analysis to investigate the biogeochemistry of food webs and sedimentary organic carbon. Although a key requirement for accurate determination of carbon transfer during manipulative experiments using compound-specific radiocarbon analysis is the availability of authentic biomarker standards of known natural abundance ${ }^{14} \mathrm{C}$ compositions, Kusch et al. point out the challenges to obtaining such standards in light of pervasive ${ }^{14} \mathrm{C}$

\section{REFERENCES}

Andersen, N. R. (ed). (1977). Concepts in marine organic chemistry. Mar. Chem. 5, 303-638. doi: 10.1016/0304-4203(77)90025-1

Benner, R. H., Lee, C., and Wakeham, S. G. (eds.). (2004). New approaches in marine organic biogeochemistry: a tribute to the life and science of John I. Hedges. Mar. Chem. 92, 1-374. Available online at: https://www.sciencedirect. com/journal/marine-chemistry/vol/92/issue/1

Farrington, J. W. (1992). Overview and key recommendations. Marine organic geochemistry workshop, January 1990. Mar. Chem. 39, 5-9. doi: 10.1016/0304-4203(92)90089-S

Hedges, J. I., Eglinton, G., Hatcher, P. G., Kirchman, D. L., Arnosti, C., Derenne, S., et al. (2000). The molecularly-uncharacterized component of nonliving organic matter in natural environments. Org. Geochem. 31, 945-958. doi: 10.1016/S0146-6380(00)00096-6 contamination of blanks arising from preparative isolation of target biomarkers obtained from algal culturing experiments. Lastly, Blattmann et al. describe a new liquid chromatographic method for isolating individual amino acids from sedimentary material for radiocarbon dating to better understand the sources, cycling, and preservation of these important compounds in marine sediments.

This volume provides a brief indication of the current state of the art and suggestions for pathways forward for some of the pressing issues and questions related to production, transformation, and fate of organic matter in the ocean. We, the workshop organizers, hope that this special issue will form the basis of further discussion and will foster future cross-disciplinary research in marine organic biogeochemistry.

\section{AUTHOR CONTRIBUTIONS}

All authors listed have made a substantial, direct and intellectual contribution to the work, and approved it for publication.

\section{ACKNOWLEDGMENTS}

The Hanse-Wissenschaftskolleg, Delmenhorst, Germany, sponsored and provided funding for the Frontiers in Marine Organic Biogeochemistry workshop in April 2019, from which the articles in this special issue were derived. We especially thank Doris Meyerdierks and staff at the HWK who contributed substantially to the success of this workshop. The workshop was also funded by the Deutsche Forschungsgemeinschaft (DFG, German Research Foundation)_project number: 422798570. The Geochemical Society provided additional funding for the conference.
Wakeham, S. G., and Lee, C. (2019). Limits of our knowledge, Part 2: selected frontiers in marine organic biogeochemistry. Mar. Chem. 212, 16-46. doi: 10.1016/j.marchem.2019.02.005

Conflict of Interest: The authors declare that the research was conducted in the absence of any commercial or financial relationships that could be construed as a potential conflict of interest.

Copyright (c) 2020 Wakeham, Lee, Arnosti, Dittmar, Hinrichs and Pearson. This is an open-access article distributed under the terms of the Creative Commons Attribution License (CC BY). The use, distribution or reproduction in other forums is permitted, provided the original author(s) and the copyright owner(s) are credited and that the original publication in this journal is cited, in accordance with accepted academic practice. No use, distribution or reproduction is permitted which does not comply with these terms. 